\title{
$\mathrm{TV}$ 시청 시 가족 구성원에 따른 $\mathrm{TV}$ 채널 선택권 영향력에 관한 연구 - 4인 가족을 중심으로 - \\ 이재동*, 신동희**
}

요 약

본 논문은 각 가족 구성원의 정보를 이용하여 가족이 $\mathrm{TV}$ 를 시청 할 때 어느 사용자가 더 많은 영향 력을 가지는지 파악한다. 가장의 수입에 따라 가정을 7단계로 세분화 하여 TV 시청 시 가장의 영향력을 분석하는 실험을 진행하였다. 가장의 수입이 높을수록 더 높은 TV 시청 시 채널 선택 영향력을 가지는 것으로 파악되었으며, 배우자의 경우 가장의 수입과 관계없이 일정한 TV 시청 시의 영향력을 가지는 것 으로 파악되었다. 그 다음, 각 가정 막내 사용자의 나이에 따른 TV 시청 시 채널 선택 영향력을 알아보 기 위한 연구에서는 막내의 나이를 4 단계로 세분화 하여 실험을 진행하였으며, 막내 사용자의 나이가 많아질수록 더 높은 TV 시청 시의 영향력을 보임을 알 수 있었다. 반대로 막내 자녀의 나이가 증가함 에 따라 가장과 배우자의 TV 채널 선택 영향력이 줄어드는 것도 알 수 있었다. 본 논문의 실험을 통해 상당히 흥미로운 결과가 도출되었고, 이는 향후 각 가정의 상황에 맞는 콘텐츠 추천 및 서비스를 제공 할 수 있을 것이라고 기대된다.

키워드 : 인구통계 정보, TV채널 선택 영향력, 각 가정 가장 및 배우자, 각 가정 가장 나이가 적은 사람

\section{A Study on the Influence of Family Member's TV Channel Selection when Watching TV Four Member Family Study}

\author{
Jaedong Lee*, Donghee Shin**
}

\section{Abstract}

In this paper, using the demographic information of each member of a family, we figured out which member of a family has more influence on channel selection. We conducted an experiment which subdivide each breadwinners' income into 7 phases, and analysis the influence when they watch TV. The breadwinners' influence on TV channel selection is increased as breadwinners' income is getting higher. In the case of spouses, they have consistent influence on TV channel selection without reference to their breadwinners' income. We conducted another experiment which subdivide the youngest person's age in each family into 4 phases to watch the influence on TV channel selection. As the youngest person grows, they have more influence. With the experiments conducted in this paper, we could draw an interesting result, and this result is expected to provide good services such as content recommendation by considering the context of each family.

Keywords : Demographic information, TV channel selection, breadwinner spouses, youngest person

$$
\text { 1. 서론 }
$$

\footnotetext{
※ 교신저자(Corresponding Author): Donghee Shin 접수일:2014년 02월 07일, 수정일:2014년 02월 27일 완료일:2014년 03월 14일

* 성균관대학교 전자전기컴퓨터공학과

Tel: +82-31-290-7987, Fax: +82-31-299-4937

email: ultrajaepo@skku.edu

** 성균관대학교 인터랙션 사이언스학과

$\square$ 본 연구는 지식경제부 및 한국산업기술평가관리원
}

의 산업융합원천기술개발사업(정보통신)의 일환으로 수행되었음 (001810041244, 스마트TV 2.0 소프트웨 어 플랫폼).

■ 본 연구는 교육부의 재원으로 한국연구재단의 지원 을 받아 Brain Korea 21 Plus Project의 연구결과로 수 행되었음(10Z20130000013). 
오늘날의 우리나라는 급격한 산업화와 도시화 로 인해 가정에 핵가족화가 가속화 되는 커다란 변화가 일어나고 있다. 가족 원 수가 감소하면서 가족의 형태가 변화하고 있다. 3 세대 이상의 대 가족이 감소하고 2 세대 이상의 핵가족이 증가하 고 있으며, 자녀가 없는 부부만으로 구성된 가 족, 편 부모 가족 마지막으로 1 인가족 역시 증가 하고 있다[1-3].

산업 사회의 핵가족은 혈연에 의한 조직이라 기보다는 평등주의에 입각한 애정으로 결합한다. 혈연은 끊어지기가 어렵고 따라서, 대가족 제도 는 상대적으로 안정적이다. 그러나 핵가족 제도 에서는 부모의 애정이 가정을 유지하는 기초가 되므로, 가정의 정서적 안정도 부부의 관계에 크 게 의존한다. 대가족 제도에서는 가정에서 어른 들과 자식들이 함께 있는 시간이 많았고, 그들의 관계가 밀접했으며 가정의 교육적 기능과 자녀 들의 대한 부모의 통제력 또한 강했다. 그러나 핵가족 제도에서는 가족 구성원들의 독립성이 강조되고, 부모들이 직장을 가져서 외출하는 경 우가 많아져 부모와 자녀가 멀어지기 쉽다는 특 징을 가지고 있다[4-6][7-10].

우리나라의 평균 가족원수는 시간의 흐름에 따라 수가 감소하고 있다. 1970년대 가족원수 평 균은 5명, 1990년대에는 3.7명 그리고 1995년도 에는 3.3 명으로 줄어들었다. 전통적으로 유지되 던 대가족 제도가 붕괴되고 핵가족 제도가 보편 화 되었다. 이는 전반적인 학력 수준의 향상과 더불어 여성의 사회 진출의 증가 등으로 인한 가정에서의 의사 결정 패턴이 본래의 부부중심 의 의사결정 형태에서 가족 공동 또는 자녀중심 의사결정 형태로 바뀌어졌다[11]. 특히 가족의 의사 결정시 자녀의 영향력이 증가 되었다는 사 실은 주목 할 만 한 사실이다[11-15].

이러한 사회 구조 변화에 따른 가정구조의 변 화는 각 가정의 $\mathrm{TV}$ 시청 시 채널 선택에 미치 는 각 가족 구성원의 영향력에도 변화를 가져오 게 되었을 거라는 가설과 함께 본 연구를 진행 하였다.

본 연구는 4 인 가족을 중심으로 가족 단위 $\mathrm{TV}$ 시청기록을 이용하여 각 구성원이 $\mathrm{TV}$ 시청 을 할 때 채널 선택에 미치는 영향력을 조사하 였다. 각 가정 가장의 수입에 따라 각 구성원의 채널 선택 여부에 영향을 미치는지를 조사하였
으며, 가족 구성원의 영향력이 부모 중심에서 자 녀 중심으로 역할이 증대됨에 따라 가족의 $\mathrm{TV}$ 시청 시 각 가정의 자녀 나이가 $\mathrm{TV}$ 채널 선택 에 미치는 영향을 조사하였다. 각 가정의 구성원 별 $\mathrm{TV}$ 시청 기록, 구성원들이 함께 $\mathrm{TV}$ 를 시청 한 기록을 이용하여 유사도를 비교하는 방식으 로 채널 선택에 미치는 영향력을 연구하였고 다 음과 같은 연구 목적을 설정하였다.

첫째, 각 가정, 가장의 수입에 따른 가족 구성 원의 $\mathrm{TV}$ 채널 선택 영향력을 분석하여 보고 이 를 통해 $\mathrm{TV}$ 채널 선택 시 가장이 미치는 영향 력 정도를 조사해 보고자 한다.

둘째, 각 가정 막내 자녀의 나이를 세분화 하 여 $\mathrm{TV}$ 채널 선택 시 막내 자녀의 영향력을 나 이에 따라 조사해 보고자 한다.

즉, 본 연구는 가장의 수입에 따라 $\mathrm{TV}$ 채널 선택 시 가장의 영향력을 분석하고 더불어 각 가정 막내 자녀들의 나이를 세분화하여 $\mathrm{TV}$ 채 널 선택 시 자녀의 나이에 따라 영향력을 분석 하는 연구이다. 이를 통해 각 가정의 $\mathrm{TV}$ 시청 정보를 이용하여 가장 영향력이 있는 사람을 파 악하였다.

\section{2. 관련 연 구}

\section{1 데이터 수집 및 분류 기준}

본 논문에서는 실험을 위해 $\mathrm{TNmS}$ *에 의해 수집된 데이터를 사용하였다. $\mathrm{TNmS}$ 는 시청률을 조사하는 회사이며 그 신뢰성을 검증 받았다(조 성호 · 송인덕 · 박정래, 2012). TNmS 데이터는 유료 판매 자료이며 연구 공동 기획으로 진행된 과제에서 구입하였다. 본 연구과제에서 구입한 $\mathrm{TNmS}$ 데이터는 수도권을 중심으로 1,000 가구, 24 채널, 6 개월 동안의 시청기록으로 구성되어 있 다. $\mathrm{TNmS}$ 의 데이터는 다음 (그림 1)과 같은 형 식으로 구성되어 있다.

* http://www.tnms.tv 
(그림 1) $\mathrm{TNmS}$ 데이터 구성
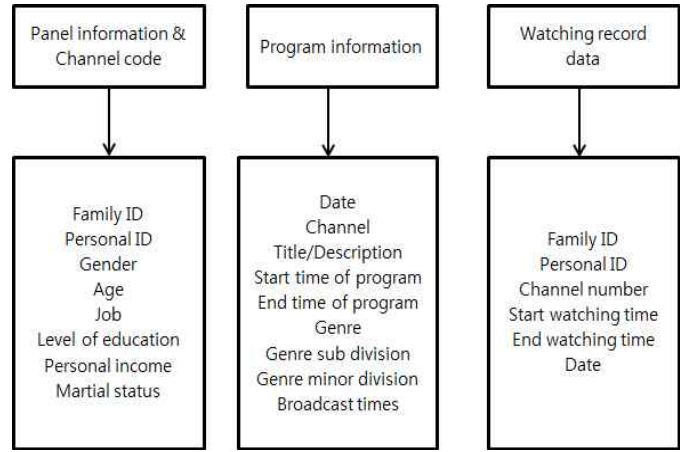

(Figure 1) TNmS data composition

위의 $\mathrm{TNmS}$ 데이터를 이용하여 각 가정의 어 떤 구성원이 무슨 프로그램을 봤는지에 대한 정 보를 얻을 수 있다.

총 1,000 가구 중 4 명으로 구성된 가정을 선택 하였다. 첫 번째 연구 목적인 각 가정, 가장의 수입에 따른 가족 구성원의 $\mathrm{TV}$ 채널 선택 영향 력 분석을 위해 264 개의 가구가 선택 되었다. 그 다음 246개의 가구에 대해서 가장의 수입 별로 가구를 나누는 작업을 진행하였다. 수입에 의해 가구를 나누는 기준은 다음 <표 $1>$ 과 같다.

<표 1> 각 가정 별 소득에 의한 분류 기준 및 선택된 가정의 수

\begin{tabular}{|c|c|}
\hline A personal income & $\begin{array}{c}\text { Selected house } \\
\text { number }\end{array}$ \\
\hline No income & 4 \\
\hline Less than $1,000,000$ won & 6 \\
\hline $\begin{array}{c}\text { More than } 1,000,000 \\
\text { Less than 2,000,000 won }\end{array}$ & 23 \\
\hline $\begin{array}{c}\text { More than 2,000,000 } \\
\text { Less than 3,000,000 won }\end{array}$ & 78 \\
\hline $\begin{array}{c}\text { More than 3,000,000 } \\
\text { Less than 4,000,000 won }\end{array}$ & 81 \\
\hline $\begin{array}{c}\text { More than 4,000,000 } \\
\text { Less than 5,000,000 won }\end{array}$ & 32 \\
\hline $\begin{array}{c}\text { More than 5,000,000 } \\
\text { Less than 6,000,000 won }\end{array}$ & 30 \\
\hline
\end{tabular}

\section{1 프로그램 저장 방법}

$\mathrm{TNmS}$ 시청률 조사 데이터에는 2013년 1월 6 월까지 6 개월 동안 각 가정의 개인 사용자 및 그룹 사용자가 시청한 $\mathrm{TV}$ 프로그램의 목록이 저장되어 있다. 하지만 각 사용자 및 그룹 사용 자가 시청한 프로그램의 목록을 비교하는 것에 
는 많은 어려움이 따르는데 그 이유는 다음과 같다. 예를 들어 어떤 가정의 1 번 사용자가 시청 한 $\mathrm{TV}$ 프로그램의 목록이 1 박 2 일, $\mathrm{MBC}$ 뉴스 등으로 저장되면 비교가 가능하지만 $\mathrm{TNmS}$ 시 청률 조사 데이터는 모든 프로그램이 고유의 제 목을 가지게 되기 때문에 문제점이 존재한다. 실 제 예를 들어 데이터를 살펴보면 다음과 같다. 1 번 사용자가 시청한 $\mathrm{TV}$ 프로그램 목록: 1 박 2 일, 1 박 2 일 설 특집, 1 박 2일 추석 특집 등으로 $\mathrm{TV}$ 프로그램의 제목이 세분화 되어 저장되는 문제점 때문에 사용자가 시청한 $\mathrm{TV}$ 프로그램 목록을 이용하여 유사도를 비교하는 것 대신 다 른 방법을 이용하였다.

본 논문에서는 각 사용자가 시청한 $\mathrm{TV}$ 프로 그램의 장르를 이용하여 사용자의 $\mathrm{TV}$ 시청 목 록을 모델링 하고자 하였다. TV 프로그램의 장 르는 총 105 개로 나뉘는데 그 중 일부를 살펴보 면 다음 <표 $3>$ 과 같다.

<표 3> TV 프로그램 장르별 세분화

\begin{tabular}{|c|c|}
\hline Category Number & Genre \\
\hline 1 & Education \\
\hline 2 & Talk show \\
\hline 3 & Current topics \\
\hline 4 & News \\
\hline 5 & Daily soap opera \\
\hline$\cdot$ & $\cdot$ \\
\hline$\cdot$ & Morning drama \\
\hline 104 & Children \\
\hline 105 & \\
\hline
\end{tabular}

$<$ Table 3> Subdivision of TV program's genre

이와 같이 장르는 105 개로 나뉘게 되고 각 사 용자는 시청한 $\mathrm{TV}$ 프로그램 장르의 시청 횟수 를 통해 105 차원의 시청 횟수 벡터로 표현이 가 능하다. 105 개의 벡터 장르는 고유한 105 개의 장 르 정보를 가지게 되고 사용자가 시청한 횟수만 큼 그 수가 올라가게 된다. 그 예를 살펴보면 다 음 (그림 2)와 같다.

(그림 2)를 보면 $\mathrm{A}$ 사용자의 시청 기록을 이용 하여, 각 프로그램 목록의 장르들의 개수를 분석
하고 105 차원의 벡터를 완성하였다. 예를 들어 $\mathrm{A}$ 사용자의 시청 기록 중, 무한도전, 1 박 2 일 등의 장르가 예능인 프로그램이 15 개가 있다면, 그 사 용자의 예능 장르 벡터의 성분은 15 가 된다. 사 용자의 시청 기록 중 시사 장르에 포함되는 프 로그램이 하나도 없다면, 시사 장르 벡터의 성분 은 0이 된다. 이렇게 완성된 105차원의 벡터를 $\mathrm{A}$ 사용자의 선호도라고 정의하고 $\mathrm{A}$ 사용자와 $\mathrm{B}$ 사 용자가 함께 본 $\mathrm{TV}$ 프로그램의 장르로 구성된 시청 기록과 비교하여 $\mathrm{A}$ 사용자와 $\mathrm{A}, \mathrm{B}$ 그룹사 용자의 시청기록 유사도를 비교하는 실험을 진 행한다.

(그림 2) 개인 사용자 및 그룹 사용자 모델링 기법

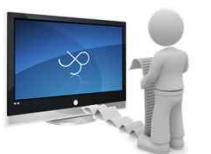

User A's watching history (1night 2days, Infinite challenge, KBS news, MBC news, current issue magazine 2580, Heritors, Nine, Response 1994 Let's eat, etc.)

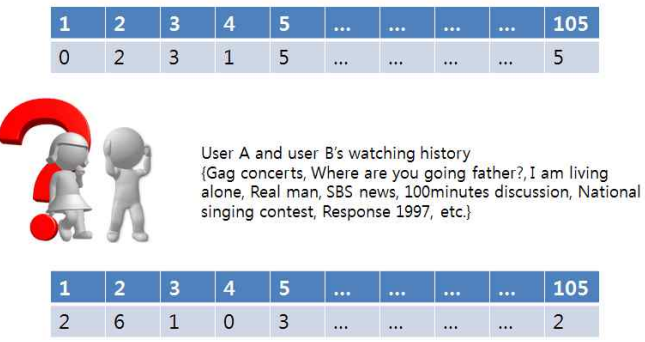

(Figure 2) Personal user and group user modeling method

3.2 각 가정 구성원의 영향력 분석 방법

$\mathrm{TV}$ 프로그램 시청 시 각 가정 구성원이 채널 선택에 미치는 영향력 조사는, 개인 사용자의 시 청기록과 그룹 사용자의 시청기록을 비교하는 방식으로 그 영향력을 평가하였다. 사용자들의 시청기록을 파악하기 위하여 $\mathrm{TNmS}$ 데이터를 이용하여 각 사용자 및 그룹 사용자가 6 개월 동 안 시청한 프로그램의 목록을 저장하였다. 예를 들어, 1 번 집의 구성원은 60 세 남자(1번 사용자), 58 세 여자(2번 사용자), 22세 여자(3번 사용자), 19 세 남자(4번 사용자)로 가정한다. 1번 집에 대 하여 2013년 1월 1일부터 6월 31일까지 1번사용 자 4 번사용자 각자가 시청한 $\mathrm{TV}$ 프로그램의 목 록을 저장하고, 그룹사용자가 시청한 $\mathrm{TV}$ 프로그 
램의 목록도 저장한다. 여기서 그룹사용자가 시 청한 $\mathrm{TV}$ 프로그램 목록은 1 번 사용자와 2 번 사 용자가 같이 $\mathrm{TV}$ 를 시청한 경우, 2 번 사용자와 3 번 사용자가 같이 $\mathrm{TV}$ 를 시청한 경우, 또는 1 번, 2 번, 3 번, 4 번 사용자가 같이 시청한 경우 등 이 며, 그때의 TV프로그램의 목록을 경우 그룹사용 자의 $\mathrm{TV}$ 프로그램 시청 목록이라고 정의하였다. 본 논문에서는 4 인 구성의 가족만을 다루었기 때문에 최대의 경우 다음 (그림 3)과 같은 경우 로 조합이 나타날 수 있다. (그림 3)의 네모는 1 번 사용자, 세모는 2 번 사용자, 마름모는 3 번 사 용자를 나타내며 마지막으로 오각형은 4 번 사용 자를 나타낸다. 그리고 원은 각 사용자 그룹 사 용자의 조합을 나타낸다. 개인 사용자의 경우 4 개의 ( $1,2,3,4$ 번 사용자) 시청 기록이 저장되고, 그룹 사용자의 경우 최대의 경우 총 11 개의 조 합이 나타나며 11 개의 시청 기록이 저장된다. 이 때 각 사용자가 가질 수 있는 조합의 개수는 자 기 자신을 제외하고 최대 7 개의 시청 기록이 저 장되게 된다. 예를 들어, 1 번 사용자의 경우 가 질 수 있는 조합은 $(1,12,13,14,123,124,134$, 1234 )가 된다. 1 은 사용자 혼자 시청한 $\mathrm{TV}$ 프로 그램의 기록이므로 비교 대상이 되지 않고 저장 된 7 개의 조합과 개인의 시청기록간의 유사도를 비교하여 유사도가 더 큰 사용자가 더 큰 영향 력을 가진다고 판단하였다.

(그림 3) 개인 사용자와 그룹 사용자의 TV 시청 목록 조합

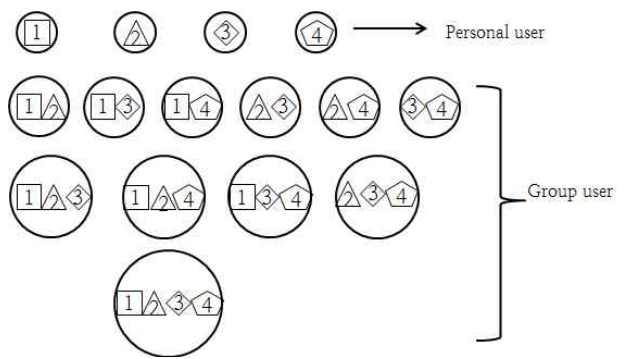

(Figure 3) Combination of TV watching history among personal user and group user

3.2 코사인 유사도를 이용한 각 사용자의 영향력 분석 기법

위의 관련연구 장에서 설명한 코사인 유사도 를 이용하여 각 사용자와 해당 사용자가 포함된
그룹 사용자의 $\mathrm{TV}$ 시청 기록의 유사도를 측정 하는 실험을 진행하였다. 코사인 유사도를 구할 수 있는 식을 살펴보면 다음과 같다.

$$
\begin{aligned}
& \text { Similarity }=\cos (\Theta)=\frac{A \cdot B}{\|A\| \cdot\|B\|} \\
& =\frac{\sum_{i=1}^{n} A_{i} \times B_{i}}{\sqrt{\sum_{i=1}^{n}\left(A_{i}\right)^{2}} \times \sqrt{\sum_{i=1}^{n}\left(B_{i}\right)^{2}}}
\end{aligned}
$$

위 식에서 $\mathrm{n}$ 은 차원을 나타내는데 본 실험에 서는 105 개의 장르 장르를 사용하였기 때문에 105 가 된다. 1,2 번 사용자가 같이 시청한 시청기 록에 대해서 1 번 사용자와 2 번 사용자의 유사도 를 구하는 과정은 다음과 같다. $\mathrm{A}$ 는 1,2 사용자가 같이 시청한 프로그램 장르의 벡터가 되고, $\mathrm{B}$ 는 1 번 사용자가 시청한 $\mathrm{TV}$ 프로그램 목록의 장르 벡터가 된다. 위의 식의 대입하여 1 번 사용자가 시청한 $\mathrm{TV}$ 프로그램의 정보와 1,2 번 사용자가 같이 시청한 프로그램의 정보의 유사도를 구한 다. 그 다음, 1,2 번 사용자가 같이 시청한 $\mathrm{TV}$ 프 로그램 장르의 벡터 정보와 2번 사용자가 시청 한 $\mathrm{TV}$ 프로그램 장르 벡터의 유사도를 구한다. 1 번 사용자와 2 번 사용자의 유사도 중 더 높은 유사도를 가진 사용자가 1 번사용자와 2 번 사용 자가 같이 $\mathrm{TV}$ 를 시청할 때 더 많은 영향력을 가진다고 평가하였다.

3.2 절에서 언급한 바와 같이 한 사용자는 최 대 7 개의 그룹시청 조합을 가질 수 있다. 따라서 1 번 사용자가 본인 혼자 시청한 $\mathrm{TV}$ 프로그램의 기록 외에 최대 7 개의 조합을 가지고 있고 각 조합에 대해서 모든 사용자의 유사도를 평가한 다. 7 개의 조합에 대해서 1 번 사용자의 유사도가 7 번 모두 가장 높을 때는 1 번 사용자의 영향력 은 $7 / 7(=100 \%)$ 가 되고, 1 번 사용자의 유사도가 5 번 높았다면 5/7( 71.4\%)가 된다. 하지만 $\mathrm{TV}$ 를 가족 구성원 모두가 같이 시청하지 않는 성향의 가족은 각 사용자에 대해 7 개의 조합이 생성되 지 않는다. 그런 경우에 1 번 사용자가 본인이 시 청한 기록 외에 5 개의 조합을 가지고 있다고 가 정 했을 때, 그 5 개의 조합 중 1 번 사용자의 유 사도가 가장 높은 경우가 3 번이라면 그 때의 1 번 사용자의 $\mathrm{TV}$ 프로그램 선택의 영향력은 $3 / 5$ $(=60 \%)$ 가 된다. 
이와 같은 방법을 이용하여, 본 연구에서는 4 명의 구성원으로 구성된 가족을 대상으로 하여 각 구성원의 $\mathrm{TV}$ 채널 선택 시 각 가족 구성원 이 가지는 영향력에 대해 평가하고 서론에서 언 급된 연구 목적을 분석하는 실험을 진행하였다.

분류된 가정들을 이용하여, 가장의 수입 및 막 내의 나이가 $\mathrm{TV}$ 채널 선택에 미치는 영향력을 분석하였다.

\section{4. 실험 및 분석}

본 장에서는 가족이 $\mathrm{TV}$ 를 시청하는 경우, 각 가장 수입에 따른 채널 선택 영향력과 각 가정 막내의 나이에 따른 $\mathrm{TV}$ 프로그램 시청시의 영 향력에 대해 실험하고 분석한다. 앞에서 언급된 분류 기준에 따라 각 가정 가장의 수입, 각 가정 막내의 나이를 분류하였고 분류된 기준에 따라 실험을 진행하여 그 차이점을 살펴본다.

4.1 각 가정 가장 수입에 따른 채널 선택 영향력 분석

본 절에서는 $\mathrm{TV}$ 채널 선택시각 가정 가장 수 입에 따른 가장의 영향력에 대해서 분석한다. 각 가정 별 가장의 수입을 수입 없음부터 600만원 이상까지 100 만원 단위로 분류하여 총 8 가지 가 정으로 분류하였다. 본 논문의 실험에 사용된 가 정은 모두 4 인으로 구성된 가정이며 가장, 배우 자, 자녀 1 그리고 자녀2로 구성되어 있다. $\mathrm{TV}$ 시청 시 각 가정 가장의 수입에 따른 채널 선택 영향력은 다음 (그림 4)와 같다.

(그림 4) 가장의 수입에 따른 가장의 채널 선택 영향력

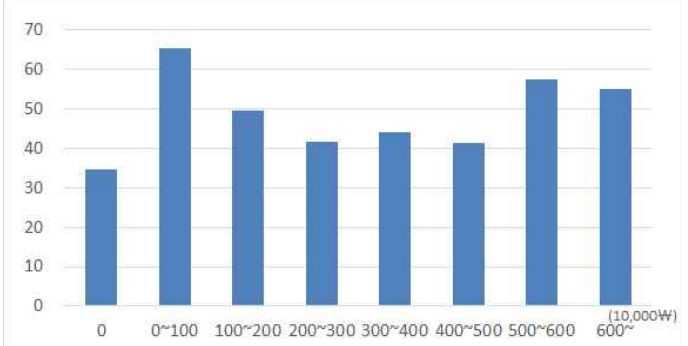

(Figure 4) TV channel selection influence of the breadwinner depends on their income
(그림 4)는 $\mathrm{TV}$ 시청 시 가장의 수입에 따른 가장의 채널 선택의 영향력에 대한 그래프이다. 가장의 수입이 없을 때 $\mathrm{TV}$ 시청의 영향력이 가 장 낮음을 알 수 있었고, 100 만원 미만일 때 영 향력이 가장 높음을 알 수 있다. 그 다음부터는 영향력이 전반적으로 낮아지는 경향을 보이는데, 가장의 수입이 500만원 이상이 되면 다시 높아 지는 현상을 나타냈다. 가장의 $\mathrm{TV}$ 시청 시 채널 선택의 영향력뿐 아니라 가장의 수입에 따라 각 가족 구성원의 $\mathrm{TV}$ 시청시의 채널 선택 영향력 을 살펴보았다. 그 결과는 (그림 5)와 같다.

(그림 5) 각 가정 가장의 수입에 의한 모든 가족 구성원의 $\mathrm{TV}$ 시청 시 채널 선택 영향력

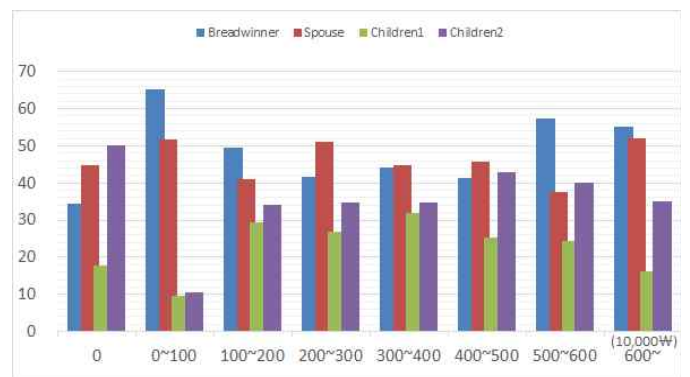

(Figure 5) TV channel selection influence of the each family member depends on the breadwinners' income

(그림 5)는 $\mathrm{TV}$ 시청 시 각 가정 가장의 수입 에 따른 모든 가족 구성원의 채널 선택의 영향 력에 대한 그래프이다. 파란색 막대인 가장은 (그림 5)와 같지만 배우자 및 자녀들의 영향력은 가장의 수입에 따라 흥미로운 결과를 보이는 것 을 알 수 있다. 먼저 대부분의 배우자들의 TV 시청시 채널 선택의 영향력은 가장의 수입에 관 계없이 비교적 일정하다는 것을 알 수 있었다. 자녀 1 의 경우에는 모든 경우에서 가장의 수입에 관계없이 가장 적은 $\mathrm{TV}$ 시청시의 영향력을 나 타내었으며 막내 자녀의 경우 가장의 수입에 따 라 많은 변화를 보이는 것을 알 수 있다. 가장의 수입이 없는 경우에 막내 자녀의 $\mathrm{TV}$ 시청 시 채널 선택의 영향력이 가장 높았지만 가장 수입 이 100 만원 미만일 때 가장 낮은 결과를 나타내 는 것은 매우 흥미로운 결과이다. 그 외의 경우 에는 자녀들의 영향력이 비슷한 정도를 보이지 만 가장의 수입이 600 만원 이상 일 때 두 자녀 
모두 상대적으로 영향력이 낮음을 알 수 있다. 모든 가정에서 부모가 자녀보다 더 높은 $\mathrm{TV}$ 시 청 시의 채널 영향력을 가지고 있다는 것과 모 든 가정에서 나이가 많은 자녀가 나이가 적은 자녀에게 $\mathrm{TV}$ 시청시의 채널 선택을 더 많이 양 보한다는 것은 흥미로운 결과이다.

\section{2 각 가정 막내의 나이에 의한 영향력 분석}

본 절에서는 $\mathrm{TV}$ 채널 선택 시 각 가정 막내 사용자의 나이에 따른 영향력에 대해서 분석한 다. 각 가정 별 막내 사용자의 나이를 $0 \sim 7$ 세, 7 14세, 15 19세 그리고 20세 이상으로 구분하여 실험을 진행하였다. 위의 가장의 수입 별 영향력 을 알아보기 위해 사용된 가정의 구성과 마찬가 지로 실험에 사용된 가정은 모두 4 인으로 구성 된 가정이며 가장, 배우자, 자녀 1 그리고 자녀2 로 구성되어 있다. 다음 (그림 6)은 $\mathrm{TV}$ 시청 시 각 가정 막내 자녀의 나이에 따른 채널 선택 영 향력을 분석한 그래프이다.

(그림 6) 각 가정 $\mathrm{TV}$ 시청 시 막내 사용자의 나이에 따른 막내 사용자의 채널 선택 영향력

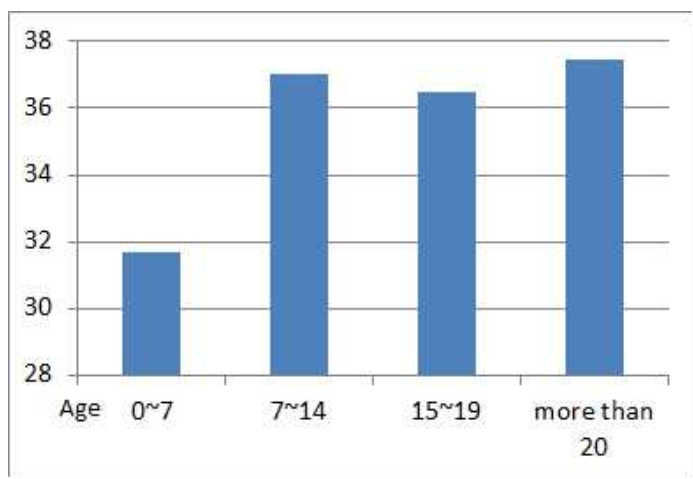

(Figure 6) TV channel selection influence of the youngest family member depends on their age

(그림 6)의 결과에 따르면 막내 자녀의 나이 가 초등학생 미만인 경우(0 7세) $\mathrm{TV}$ 시청 시 채 널 선택 영향력이 가장 적은 것으로 분석되었다. 막내 자녀의 나이가 성인인 경우 가장 높은 $\mathrm{TV}$ 시청 시 채널 선택 영향력을 나타내었지만 막내 자녀의 나이가 초등학생인 경우(8 13세) 부터 성
인이 경우(20세 이상)까지의 결과가 큰 차이를 나타내지는 않았다. 막내 자녀의 나이가 초등학 생 미만인 경우 가장 적은 $\mathrm{TV}$ 시청 시 채널 선 택 영향력을 나타내었다는 것은 $\mathrm{TV}$ 를 시청할 때 막내 자녀의 의사가 반영되지 않았고, 이는 막내 자녀의 나이가 의사를 반영하기에는 불충 분하였기 때문이라고 판단된다. 반면에, 성인의 경우가 가장 영향력이 높은 이유는 막내 자녀의 나이가 20세 이상이 되면서 본인이 원하는 $\mathrm{TV}$ 채널 의사를 보다 더 정확하게 전달하였다고 판 단된다. 다음 (그림 7) 는 각 가정 막내 자녀의 나이에 따라 $\mathrm{TV}$ 채널 시청 시 모든 가족 구성 원의 $\mathrm{TV}$ 시청 시 채널 선택 영향력을 나타내는 그래프이다.

(그림 7) 각 가정 막내 사용자의 나이에 따른 모든 가족 구성원의 TV 시청 시 채널 선택 영향력

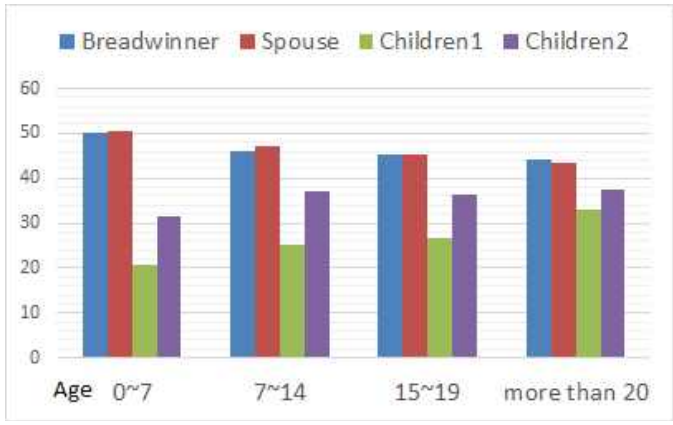

(Figure 7) TV channel selection influence of the each family member depends on the age of youngest person

위의 (그림 7)의 결과를 보면 앞선 실험과 같 이 막내 자녀의 나이가 증가 할수록 $\mathrm{TV}$ 채널 선택에 영향력이 높아지는 것을 알 수 있고 상 대적으로 막내 자녀의 나이가 증가함에 따라 가 장과 배우자의 채널 선택 영향력이 줄어드는 것 을 알 수 있다. 앞에서 언급된 바와 같이 자녀의 나이가 증가함에 따라 본인이 시청하고자 하는 $\mathrm{TV}$ 프로그램의 의사를 전달하는 역량이 더 높 아졌다고 판단된다. 각 가장의 수입에 의해 $\mathrm{TV}$ 채널의 영향력을 분석한 것과 마찬가지로 첫째 자녀가 막내 자녀에게 양보하는 모습 역시 관찰 된다. 


\section{5. 결론 및 향후 연구}

본 논문은 각 가족 구성원의 정보를 이용하여 가족이 $\mathrm{TV}$ 를 시청 할 때 어느 사용자가 더 많 은 영향력을 가지는지 분석해 보았다. 각 가장의 수입에 따라 가장의 영향력을 분석하는 실험에 서는 가장이 수입이 없을 때 가장 낮은 $\mathrm{TV}$ 채 널 선택에 영향력을 보임을 알 수 있었고, 가장 의 수입에 100 만원 미만일 때 가장 높은 영향 력을 가짐을 알 수 있었다. 하지만 그 표본의 수 가 너무 적어 더 많은 표본을 확보하여 검증을 하는 것이 필요하다. 그 외의 가장수입의 경우에 는 가장의 수입이 높을수록 더 높은 $\mathrm{TV}$ 시청 시 채널 선택 영향력을 가지는 것으로 파악되었 다. 배우자의 경우 가장의 수입과 관계없이 일정 한 $\mathrm{TV}$ 시청 시 채널 선택 영향력을 가지며, 모 든 경우에서 가장과 배우자(부모)가 자녀들보다 더 높은 $\mathrm{TV}$ 시청시의 채널 선택 영향력을 보였 다.

$\mathrm{TV}$ 시청 시 각 가정 막내 사용자의 나이에 따른 채널 선택 영향력을 알아보기 위한 연구에 서는 막내의 나이를 4 그룹으로 세분화 하여 실 험을 진행하였으며, 막내 사용자의 나이가 많아 질수록 더 높은 $\mathrm{TV}$ 채널 선택에 영향력을 보임 을 알 수 있었다. 이는 막내 사용자의 나이가 증 가함에 따라 본인이 시청하고자 하는 $\mathrm{TV}$ 프로 그램을 더욱 더 적극적으로 표현했다고 생각된 다. 반대로 막내 자녀의 나이가 증가함에 따라 가장과 배우자의 $\mathrm{TV}$ 채널 선택 영향력이 줄어 드는 것도 알 수 있었다.

본 연구를 통해 각 가정의 수입과 막내 자녀 의 나이에 따른 $\mathrm{TV}$ 채널 선택 시 각 가족 구성 원이 가지는 영향력에 대해 알아보았다. 그 결 과, 상당히 흥미로운 결과가 도출되었고, 이는 향후 각 가정의 상황에 맞는 콘텐츠 추천 및 서 비스를 제공할 수 있을 것이라고 파악된다[16] 더불어 각 가정의 수입과 막내 자녀의 나이뿐 아니라 더 많은 정보를 이용하여 각 가족 구성 원의 $\mathrm{TV}$ 시청 시 채널 선택 영향력을 파악한다 면 더욱더 세분화 되고 정확한 각 가족 구성원 의 영향력이 파악 될 것이라고 기대한다.

\section{References}

[1] Yunmin Lee, "A study on role participation of the family purchasing decision-making", A master's thesis, Sookm,y ung Women's Univsersity, South Korea, 1985.

[2] National Statistical Office, Estimated Future household(200 2), Daejeon: National Statistical Office, 2002.

[3] National Statistical Office, 2005 - 2030 Estimated Future household, Daejeon: National Statistical Office, 2002.

[4] Jinyoung Park, "A Study on the Role of Children in the Family Dining Decision Making Process", Korea Academi c Society of Tourism Management, Vol.2, pp. 143-161, 1997.

[5] Kyungja Doo, Hyesun Jung, "A study on Participation-Type $s$ of the Family in the Purchasing Decision-Making", Kore an Family Resource Management Association, Vol.5, No. 1, pp. 15-31. 2001.

[6] Haksik Lee, Heejung Lee, "A study on the Role of Children in the Family Purchase Decision Making Process", Korea n Society of Consumer Studies, Vol.2, No.1, pp. 1-12, 1991.

[7] Isabella C. M. Cunningham, Robert T. Green, "Purchasing Roles in the US Family, 1955 and 1973", Journal of Marketi ng, Vol.38, No.4, pp. 61-64. 1974.

[8] William K D, Lim J. S, "Family Decision Making in Leisure time Activities: An Exploratory Investigation of the Impac t of Locus of Control, Child Age Influence Factor and Pare ntal Type on Perceived Children Influence", Advanced in Consumer Research, Vol.13, pp. 370-374. 1986.

[9] Belch, M, Willis, L, "Family decision at the turn of the centur $y$ : Has the changing structure of households impacted the family decision-making process?", Journal of Consumer Behavior, Vol.2, No.2, pp. 111-124. 2002.

[10] Flurry, L., Burns, A, "Children's influence in purchase decis ions: a social power theory approach", Joumal of Business Research, Vol.58, No.5, pp.593-601, 2005.

[11] Moore-Shay E. S., Wilkie W. L. Recent, "Development in 
Research on Family Decisions", Advances in Consumer Research, Vol.15, pp 454-460. 1988.

[12] Inhui Gu, "How Family Background Impact the Youth's Educational Attainment - Focusing on the Family Struct ure, Family Income and Poverty", Korean Academy of Social Welfare, pp. 473-497, 2003.

[13] Sungtai Hong, Woonbong Na, "Influence Patterns in Purch ase Decision Making in Korean and Singapore Family", Marketing Management Research, Vol.10, No.1, pp. 77-94, 2005.

[14] Hanjoon Lee, Kyungjin Kim, Jongchul Park, "The Purchase Influence of Elderly parents in Extended Families", Korea n Society of Consumer Studies, Vol21, No.2, pp. 395-416, 2010.

[15] Injae Lee, Minho Cho, "A Test of Adaptability of Olson's Circumplex Model to Family decision Making - Focused on Children Influence-", Korea Academic Society of Touri sm Management, Vol.24, No.2, pp.315-334, 2009

[16] Wonjae Lee, Nam-Yong Lee, Jone-Bae Kim, “An Empirical Study on Forecasting Model of Popularity Rating for Drama Programs", Journal of Digital Con tents Society, Vol.13, No.3, Sep, 2012.

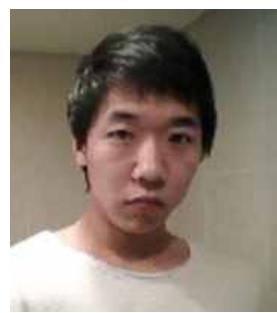

2011년 : 단국대학교 (컴퓨터과학과)

2013년 : 성균관대학교 대학원 (전자전기 컴퓨터 공 학)

2009년 2011년: 단국대학교 2011년 현재: 성균관대학교 대학원 관심분야: 데이터 마이닝(Data Mining), 패턴 인식 (Pattern Recognition)

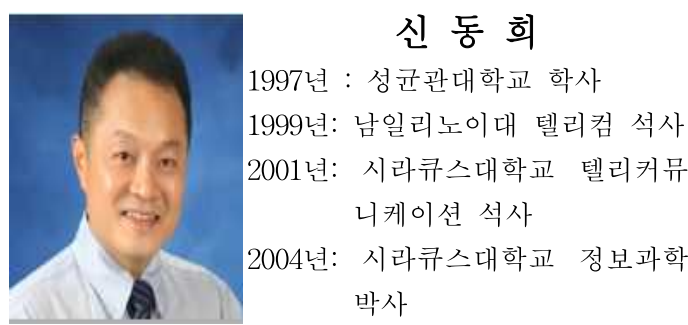

2002년 2004년: Syracuse University 강사

2004 2009년: Penn State University 조교수

2009 현재: 성균관대 인터랙션 사이언스 부교수, 학과장, 연구소장

관심분야 : 인간-컴퓨터상호작용, 인터랙션, 스마트 콘텐츠, 정보통신경영, 커뮤니케이션 